\title{
Driving Factors of Carbon Emissions in China's Logistics Industry
}

\author{
Shuangjiao Lin ${ }^{1,2}$, Jian Wang ${ }^{1,2 *}$ \\ ${ }^{1}$ Institute of Economics and Management, Fuzhou University, Fuzhou, 350116, China \\ ${ }^{2}$ Logistics Research Center, Fuzhou University, Fuzhou, 350116, Fuzhou, China
}

Received: 1 March 2021

Accepted: 23 June 2021

\begin{abstract}
Developing low-carbon logistics requires an understanding of the driving factors for carbon emissions. We employed the Comparative Study on Urban Transport and the Environment (CUTE) framework to identify the driving factors of China's logistics carbon emissions. Then, the Generalized Fisher Index Decomposition (GFID) model was adopted to decompose the effects of the driving factors. Finally, we tracked the spatial dynamics trajectory of each driving effect based on the gravity model. Our results showed that technical intensity and transport structure promoted carbon emissions, while technical efficiency and agglomeration curbed carbon emissions. The gravity centers of transport structure and technical efficiency converged with that of carbon emissions, whereas the gravity centers of technical intensity and industry agglomeration diverged from that of carbon emissions. The driving effects showed an obvious spatial heterogeneity, which indicated that carbon reduction policies should be formulated according to the local situation.
\end{abstract}

Keywords: logistics industry, carbon emissions, driving factors, CUTE framework, GFID model

\section{Introduction}

With the acceleration of economic globalization, the connection between industries is becoming increasingly complicated. The rapid development of various industries in the supply chain is accompanied by increasing demand for logistics activities. Logistics is an important link in promoting the economic development in China, playing a vital role in the production, circulation, and consumption of goods and services. The logistics industry has generated a large amount of carbon emissions because of its inefficient

*e-mail: fzu715@126.com operation mode and irrational transport structure. Consequently, the sector is facing increasing pressure to reduce its carbon emissions. Thus, the crucial issue is to identify the major driving factors of carbon emissions from China's logistics industry, which can be the breakthrough point to achieve a low-carbon development logistics industry.

Since the 1970s, research on changes in carbon emissions and their driving factors has gradually become a hot issue in the theoretical community. Related research can be divided into two categories. A part of the research focuses on changes in indoor carbon emissions [1] and its influencing factors [2]. Related research mainly focuses on the impact of indoor plants on carbon concentration [3]. The other part of the research focuses on changes in outdoor 
carbon emissions and their driving factors [4]. This type of research mainly discusses changes in national carbon emissions and their driving factors from a macro perspective [5]. Few studies have explored the impact of logistics industry-level factors on response letter this industry's carbon emissions. Therefore, this study aims to explore the driving factors of China's logistics carbon emissions from the perspective of the logistics industry itself.

The use of appropriate methods to decompose the driving factors of China's logistics carbon emissions is one of the main objectives of this study. The most commonly used decomposition methods include structure decomposition analysis (SDA) and index decomposition analysis (IDA). Among them, the SDA method was developed on the basis of the Inputoutput Analysis method and is mainly used for the decomposition of hidden driving factors for carbon emissions [6]. However, the SDA method has high data requirements and is difficult to apply to the decomposition of the driving factors in the logistics industry [7]. In contrast, the IDA method has a comparably low data requirement, but its formula contains a logarithmic term that cannot accommodate negative values; the most common method to solve this issue is to use a minimum value to replace negative values, but this will inevitably lead to a certain deviation in the result [8]. The Fisher index can effectively overcome the above problems [9]. The traditional Fisher index decomposition model only contains two sub-factors. Ang et al. [10] extended the Fisher index decomposition model and proposed the Generalized Fisher Index Decomposition (GFID), which can apply the traditional two-factor Fisher index model to the multi-factor field. The GFID method has passed the factor interchange, time interchange, ratio, zero value robustness, and negative value robustness tests; thus, it is superior to the SDA and IDA methods.

In addition, the geographical space of China is enormous. Inter-provincial logistics activities are frequently linked; however, significant regional differences in resource endowments, industrial structure, and technical level lead to a notable spatial heterogeneity in the driving effects. The focus of existing literature is mainly on the spatial dynamics of pollution emissions. For example, Tong et al. [11] studied the spatial dynamics of China's carbon emissions based on the perspective of spatial agglomeration and found that China's carbon emissions have significant spatial agglomeration characteristics, which are gradually increasing. Zhang and Wei [12] combined the metafrontier approach with the non-radial Luenberger productivity indicator to investigate the dynamic changes in the total factor carbon emissions performance of China's transportation sector. The study found that the central region of China had the largest increase in carbon emissions performance, followed by the eastern and western regions. Based on continuous high-resolution satellite images and the carbon emissions factor method, Pei et al. [13] explored the spatial dynamics of carbon emissions in Guangdong Province, China, and found that these emissions were in an agglomeration and increasing stage, especially in the Pearl River Delta and northern Guangdong. However, to the best of our knowledge, few studies have explored the spatial dynamics of the driving factors that cause environmental pollution from a spatial perspective, particularly focusing on the driving effects of logistics carbon emissions. Therefore, it is necessary to calculate and track the changing trajectory of various driving factors in the spatial dimension. Accordingly, we investigated the driving factors of logistics carbon emissions in 29 provinces of China from 2003 to 2018 (Hainan was not included because of missing data; Chongqing was included in Sichuan Province for this investigation).

Based on previous studies, this study makes contributions to the following aspects: (1) adopting the recognition-decomposition research framework, we introduced the Comparative Study on Urban Transport and the Environment (CUTE) model to identify the driving factors of logistics carbon emissions. Subsequently, we introduced the GFID model to decompose the driving effects of the factors, which help to scientifically and reasonably determine the impact of economic behavior on carbon emissions. (2) We adopted gravity models in the field of physics to explore the spatial dynamics of various driving effects from the spatial dimension, which is conducive to determine the spatial heterogeneity of the driving effects. This study has certain implications for local government departments in formulating policies for the reduction of logistics carbon emissions based on local conditions.

The remainder of this paper is organized as follows. In Section 2, we categorize the factors that cause changes in carbon emissions based on the CUTE model. We introduce the main research methods and data sources in Section 3. We employed the GFID model to decompose the driving effects of logistics carbon emissions and the gravity model to measure the spatial dynamic trajectory of the gravity center of each driving effect. These aspects are discussed in Section 4. Section 5 presents a summary of the results of the study and suggests policy recommendations.

\section{Materials and Methods}

\section{Identification of Driving Factors Based on the CUTE Framework}

Grossman and Krueger [14] proposed an environmental three-effect model to identify the main driving factors of environmental problems from scale, structure, and technical effects. Hayashi and Nakamura [15] suggested a CUTE framework 
by analyzing the carbon sources of transportation activities from three aspects, i.e., reducing the scale of transportation activities, changing transportation modes, and improving transportation efficiency. Luo et al. [16] explored the key driving factors of carbon emissions according to the low-carbon transportation activities mentioned above. However, because of the robust growth trend in the Chinese economy, reducing the logistics scale is difficult to achieve. Moreover, it is unrealistic to achieve carbon reductions by curtailing or avoiding the expansion of logistics activities. Yao et al. [17] suggested that industry agglomeration could achieve carbon reductions using scale effects, competition effects, and network effects, which would ultimately reduce environmental pollution with the expansion of the economic scale. Industry agglomeration would, therefore, alleviate the problem of carbon emissions caused by an expansion in the logistics industry scale. Accordingly, we employed the CUTE framework to identify the driving factors of emissions based on the three low-carbon transportation activities of avoiding economic scale expansion, transforming transportation modes, and improving energy efficiency, as illustrated in Fig. 1.

\section{Industry Agglomeration}

Existing research has not reached a consistent conclusion on agglomeration and carbon emissions. The main points can be summarized in two aspects. First, some studies show that industry agglomeration plays a critical role in curbing carbon emissions by exerting economic scale and technology spillover effects. Zhang [18] put forward that industry agglomeration has a huge spatial spillover capacity, which partially breaks the high carbon lock of coal. Based on the perspective of a circular economy, industry agglomeration has significant benefits to the recycling of resources, such that it can alleviate pollution emissions [19]. However, some studies present completely opposite conclusions. They found that when industry agglomeration partially develops, it will produce a crowding effect, i.e., an imbalance in the factor ratio caused by agglomeration will cause diseconomies of scale and promote carbon emissions in the logistics industry. Wen and Liao [20] found that, with an increase in the economic scale, industry agglomeration will increase energy consumption, which in turn promotes the growth of carbon emissions. Chen et al. [21] conducted an empirical test on the carbon emissions of industry agglomeration at the municipal level in China, finding that industrial agglomeration promotes carbon emission growth, while reducing carbon emission intensity. Accordingly, industry agglomeration is regarded as a key driving factor in curbing carbon emissions.

\section{Transport Structure}

Changing the transportation mode is the key factor in achieving low-carbon logistics activities. The transformation of the transportation mode mainly realizes low-carbon logistics by controlling the ratio of road and air transportation, and developing railway and waterway transportation, i.e., driving the low-carbon development of the logistics industry by optimizing the transport structure. Related studies have confirmed this view. Dai and Gao [22] regard the transport structure as a critical factor in the carbon emissions of the logistics industry. Saidi and Hammami [23] contend that an irrational transport structure has a significant effect on environmental degradation. Luo et al. [24] analyzed the driving factors of the freight industry in three major regions in China, finding that transport structure is a crucial driving factor for changing carbon emissions. Guo and Meng [25] narrowed the scope of their study to the Beijing-Tianjin-Hebei region, also finding that transport structure has a significant impact on the carbon emissions of the sector.

\section{Technical Innovation}

Improving energy efficiency is another activity conducive to achieving low-carbon logistics; technical innovation is an important pathway to an improved energy efficiency. Shao et al. [26] introduced three indicators, i.e., research and development (R\&D) intensity, investment intensity, and R\&D efficiency, to explore the effects of technical innovation on carbon emissions. Their results support the finding that technical innovation is a crucial driving force for improving energy efficiency. Cui and Li [27] pointed out that technical innovation has a significant influence on the carbon emissions of transportation. Yang and $\mathrm{Li}$ [28] proposed that improving technical intensity would

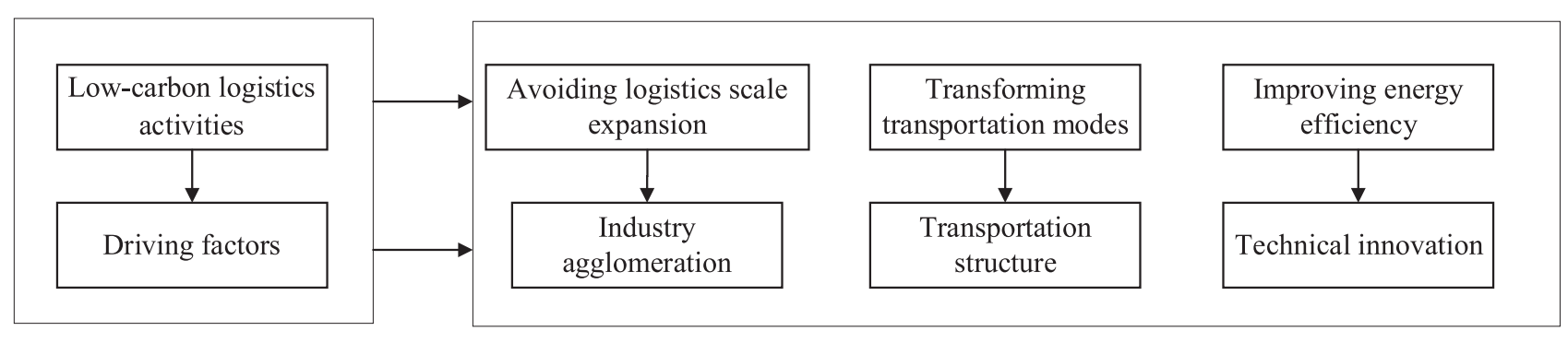

Fig. 1. Identification of driving factors of logistics carbon emissions. 
increase energy consumption, thereby promoting an increase in carbon emissions, which would partially offset carbon reductions due to the improvement of technical efficiency. It follows that technical innovation is a major driving force of energy efficiency.

\section{Carbon Emissions Calculation}

According to the top-down method proposed by the IPCC [29], we calculated the logistics carbon emissions from each transport mode and then summed these values. The calculation formula is:

$$
C^{t}=\sum_{i} C_{i}^{t}=\sum_{i} \sum_{j} C_{i j}^{t}=\sum_{i} \sum_{j} V_{i j}^{t} \times C F_{i j}^{t} \times E C_{j}
$$

...where $C$ represents logistics carbon emissions; $t$ represents the year; $i$ represents the transportation mode; and $j$ represents the energy type. The main types of energy consumed by railway transportation are diesel, electricity, and coal. Road transportation mainly consumes diesel and gasoline, while aviation transportation mainly consumes kerosene. Water transportation mainly consumes diesel, whereas pipeline transportation mainly consumes fuel oil and electricity. In Eq. (1), $V$ represents the freight turnover; $C F$ is the energy consumption coefficient; and $E C$ is the carbon emissions factor.

\section{Extended Kaya Identity}

The Kaya identity is a common method for analyzing the driving factors of carbon emissions [30], which can be expressed as follows:

$$
C=\frac{C}{E} \times \frac{E}{Y} \times \frac{Y}{P} \times P
$$

...where $E$ is the energy consumption; $Y$ is the GDP; and $P$ is the population. We incorporated the transport structure, technical innovation, and industry agglomeration into the Kaya identity based on the identification results of the driving factors. Equation (2) can be extended to:

$$
\begin{aligned}
C=\sum_{i}^{m} \sum_{r}^{n} C_{i r} & =\sum_{i}^{m} \sum_{r}^{n} \frac{C_{i r}}{V_{i r}} \times \frac{V_{i r}}{V_{r}} \times \frac{V_{r}}{R_{r}} \times \frac{R_{r}}{W_{r}} \times \frac{W_{r}}{W} \times \frac{Y}{Y_{r}} \times \frac{Y_{r}}{Y} \times W \\
& =\sum_{i}^{m} \sum_{r}^{n} C F_{i r} \times T S_{i r} \times T E_{r} \times T I_{r} \times A G_{r} \times W C_{r} \times E C
\end{aligned}
$$

...where $i$ represents the transport mode; $m$ represents the total number of transport modes; $r$ represents the province; and $n$ represents the total number of regions. Therefore, $C_{i r}$ is the carbon emissions generated by the transportation mode $(i)$ in province $(r) ; V_{i r}$ is the freight turnover of the transportation mode $(i)$ in province $(r)$; $V_{r}$ is the total freight turnover in province $(r) ; R_{r}$ is the number of logistics patent authorizations in province $(r)$;
$W_{r}$ is the logistics added value in province $(r) ; Y_{r}$ is the GDP in province ( $r) ; Y$ is the GDP in China; and $W$ is the logistics added value in China. Therefore, $C F_{i r}=C_{i r} / V_{i r}$ is the carbon emissions coefficient of the transportation mode (i) in province $(r)$ and $T S_{i r}=V_{i r} / V_{r}$ is the transport structure of province $(r)$. Logistics technology innovations are measured through two indicators [31], where $T E_{r}=V / R_{r}$ is the logistics technical efficiency of province $(r), T I_{r}=R_{r} / W_{r}$ is the logistics technical intensity of province $(r), A G_{r}=\left(W_{r} / W\right)(Y / Y)$ is the logistics industry agglomeration level of province $(r), W C=Y / Y$ is the regional development level, and $E C=W$ is the national logistics activity scale.

\section{GFID Model}

To decompose the driving effects of each factor on logistics carbon emissions, we adopted the GFID model based on the extended Kaya identity mentioned above [10]. The GFID model extends the traditional two-factor Fisher index decomposition method to multi-factor fields, expressed as:

$$
C=\sum_{i}^{m} C_{i}=\sum_{i}^{m} X_{1 i} X_{2 i} \ldots X_{n i}
$$

...where $C$ is the total index, representing logistics carbon emissions; $X_{1}, X_{2}, \ldots, X_{n}$ represent the driving factors; $i$ represents the subcategory of $C$; and $m$ represents the total number of subcategories, which represents the five transportation modes of the logistics industry. The influence of $X_{1}, X_{2}, \ldots, X_{n}$ on the change in the entire index from year 0 to year $t$ is shown by:

$$
D=\frac{C^{T}}{C^{0}}=\frac{\sum_{i} X_{1 i}^{T} X_{2 i}^{T} \ldots X_{n i}^{T}}{\sum_{i} X_{1 i}^{0} X_{2 i}^{0} \ldots X_{n i}^{0}}=D_{X_{1}} D_{X_{2}} \ldots D_{X n}
$$

Given that $N=\{1,2, \ldots, n\}$, its cardinality is $n ; S$ is a subset of $N$, and its cardinality is $S^{\prime} . C(S)=\sum\left(\prod_{l \in S} X_{l}^{T} \prod_{m \in N \backslash S} X_{m}^{0}\right)$ and $C(\phi)=\sum\left(\prod_{m \in N} X_{m}^{0}\right)$, where $\varnothing$ is a null set. Following the principle of the geometric average, we decomposed $C^{T} /$ $C^{0}$ into $n$ components, among which the component $X_{j}=(1,2, \ldots, n)$ represents the driving factor $(j)$. Then, the decomposition result of driving factor $(j)$ is calculated as:

$$
D_{X_{j}}=\prod_{\substack{S \subset N \\
j \in S}}\left[\frac{V(S)}{V(S \backslash\{j\})}\right]^{\frac{1}{n} \frac{1}{\left(\begin{array}{c}
n-1 \\
s^{\prime}-1
\end{array}\right)}}=\prod_{\substack{S \subset N \\
j \in S}}\left[\frac{V(S)}{V(S \backslash\{j\})}\right]^{\frac{\left(s^{\prime}-1\right) !\left(n-s^{\prime}\right) !}{n !}}
$$

Combining Eq. (3) and (5), the decomposition result of the driving factors of logistics carbon emissions from year 0 to year $t$ year is:

$$
D_{t o t}=\frac{C^{T}}{C^{0}}=D_{c f} D_{t s} D_{t e} D_{t i} D_{a g} D_{w c} D_{e c}
$$


...where $D_{\text {tot }}$ represents the change in carbon emissions; the driving effect of each factor can be calculated using Eq. (6).

In Eq. (7), a driving effect greater than 1 indicates that the factor has a positive effect on logistics carbon emissions, a value of less than 1 indicates that the factor has a negative inhibitory effect on such emissions, and a value equal to 1 indicates that this factor has no influence on logistics carbon emissions.

\section{Gravity Model}

We introduced the gravity model from the field of physics to derive the gravity center of the driving effects to explore the transfer trajectory of each driving effect. The formula for the coordinates of the gravity center is:

$$
X_{t}^{d}=\frac{\sum_{r=1}^{n} m_{r, t}^{d} x_{r}}{\sum_{r=1}^{n} m_{r, t}^{d}}, \quad Y_{t}^{d}=\frac{\sum_{r=1}^{n} m_{r, t}^{d} y_{r}}{\sum_{r=1}^{n} m_{r, t}^{d}}
$$

...where $r$ represents the province; $d$ represents a driving factor; $t$ represents a specific year; $x_{r}$ and $y_{r}$ represent the longitude and latitude coordinates of the capital city in the province (r), respectively; and $m_{r, t}^{d}$ is the driving effects of driving factor $(d)$ in province $(r)$. The shift direction in the gravity center points to the high-density area of the driving effects, indicating that the driving effects in the shift direction are higher than in other regions.

\section{Data Sources}

We extracted data on freight turnover, added value, and energy consumption from the China Statistical Yearbook (2004-2019). The corresponding carbon emission coefficients for various energy sources were sourced from the 2006 IPCC National Greenhouse Gas Inventory Guidelines. In Eq. (3), the number of logistics patent authorizations derives from the China Industry Patent Information Database. Price-related data was adjusted based on 2003 to eliminate the effects of price fluctuations.

\section{Results and Discussion}

Results

\section{Calculation Results of Carbon Emissions}

We drafted a radar chart of the carbon emissions in $2003,2007,2011,2015$, and 2018 to clearly portray the carbon emissions of the logistics industry in China (Fig. 2). The regional concentrations of carbon emissions were relatively high. In 2018, the logistics industry in Hebei showed the largest volume of carbon emissions, reaching 145 million tons, which could be ascribed to the low proportion of railway and waterway freight turnover in the province. Shandong, Guangdong, and Anhui also recorded substantial emission volumes. The logistics industry in these four provinces produced 471 million tons of carbon dioxide in 2018, accounting for $34.36 \%$ of the total annual carbon emissions. The least amount of carbon emissions produced by the logistics industry were recorded in Tibet, Qinghai, Ningxia, Beijing, and Tianjin. In 2018, these five provinces generated 34 million tons of carbon emissions, accounting for only $2.46 \%$ of the total annual carbon emissions in China. From 2003 to 2018, Jiangxi Province had the largest increase in logistics carbon emissions, with an average annual growth rate of $20.79 \%$, followed by Anhui and Henan, with average annual growth rates of 19.10 and $17.38 \%$, respectively. We note that the carbon emissions in Tianjin showed a downward trend, with an average annual growth rate of $-2.95 \%$.

\section{Decomposition Results of Driving Factors}

We employed the ArcGIS software to draft the decomposition results of the driving factors from 2003 to 2018 (Fig. 3). The heterogeneity of the change in logistics carbon emissions was notable. The four inland provinces showed the largest increases, led by Jiangxi at a $D_{t o t}$ value of 21.34 , followed by Henan, Guizhou, and Hebei at $D_{t o t}$ values of 13.61, 13.28, and 12.94, respectively. The Beijing and Shanghai provinces in the eastern coastal region showed the lowest increase in carbon emissions at $D_{t o t}$ values of 2.87 and 3.53, respectively. The characteristics that these two provinces have in common are that the promotional effect of the transport structure on carbon emissions was insignificant, as well as the fact that the carbon

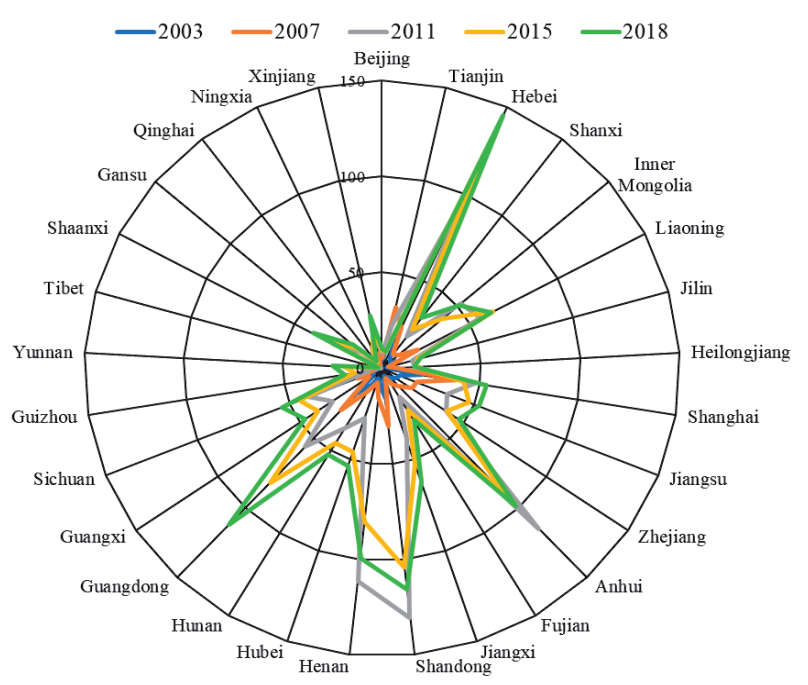

Fig. 2. Carbon emissions of the logistics industry (unit: million ton). 
reductions effect of technical efficiency was notably higher than in other regions.

To understand the timing dynamics of the driving factors, we divided the driving forces of the transport structure, technical efficiency, technical intensity, and industry agglomeration into four stages based on the time dimension; we analyzed their driving effects and the time-series variation characteristics.

The driving effect and its timing characteristics of the transport structure on logistics carbon emissions is displayed in Table 1. In general, from 2003-2018, the average value of the transport structure effect was 2.07 , i.e., it played an active role in promoting logistics carbon emissions. However, the transport structure effect of Guangdong (0.84) and Tibet (0.81) was lower than 1, i.e., inhibiting the growth of such emissions. Viewed in stages, the transport structure effect showed an "inverted U-shape" change process. From 2003 to 2011, there was an increase in the accelerating effect of the transport structure on carbon emissions. From 2011 to 2018, the transport structure effect showed a downward trend. The transport structure effect of Beijing, Liaoning, Jilin, Heilongjiang, Shanghai, Fujian, Shandong, Guangdong, Sichuan, Tibet, Ningxia, and Xinjiang dropped to below 1 .

Table 2 lists the driving effect that technical efficiency has on logistics carbon emissions and its timing characteristics. In general, from 2003 to 2018, the average value of the technical efficiency effect was 0.46 , indicating that the technical efficiency had an inhibitory effect on carbon emissions. The technical efficiency effect of only four provinces (Inner Mongolia, Jiangxi, Tibet, and Xinjiang) was greater than 1, implying that technical efficiency improvement has not provided carbon reduction effects. Viewed in stages, the effect of technical efficiency showed an "N-shaped" change. From 2003 to 2011, the impact of technical efficiency on logistics carbon emissions acted like a double-edged sword. The technical efficiency effect in provinces such as Beijing and Tianjin was lower than 1, which had a negative inhibitory effect on carbon emissions. The technical efficiency effect of provinces such as Hebei and Inner Mongolia exceeded 1. From 2011 to 2018, the carbon reductions effect of technical efficiency reappeared, but the emissionsreduction effect was slightly weakened.

Table 3 displays the driving effect of technical intensity on carbon emissions and its time-series change. Technical intensity was the core driving factor of the increase in logistics carbon emissions, with an average driving effect value of 4.30 from 2003 to 2018. Viewed in stages, the effect of technical intensity showed a volatile upward trend. From 2003 to 2011, the positive promotional effect of technical intensity on carbon emissions declined slightly. From 2011 to 2015, the technical intensity effect value rebounded because of the rebound effect of technical progress. From 2015 to 2018, two types of notable changes occurred in the technical intensity effect compared with the period from 2011 to 2015. 1) Fourteen provinces, i.e., Tianjin, Hebei, Inner Mongolia, Jilin, Fujian, Jiangxi, Henan, Guangdong, Sichuan, Guizhou, Tibet, Shaanxi, Ningxia, and Xinjiang, showed an increase in the technical intensity effect, indicating that the expansion of the logistics scale caused by logistics technology innovation in these regions completely or partially offset the energy-savings effect from technical progress. 2) In the other provinces, such as Beijing, Shanxi, and

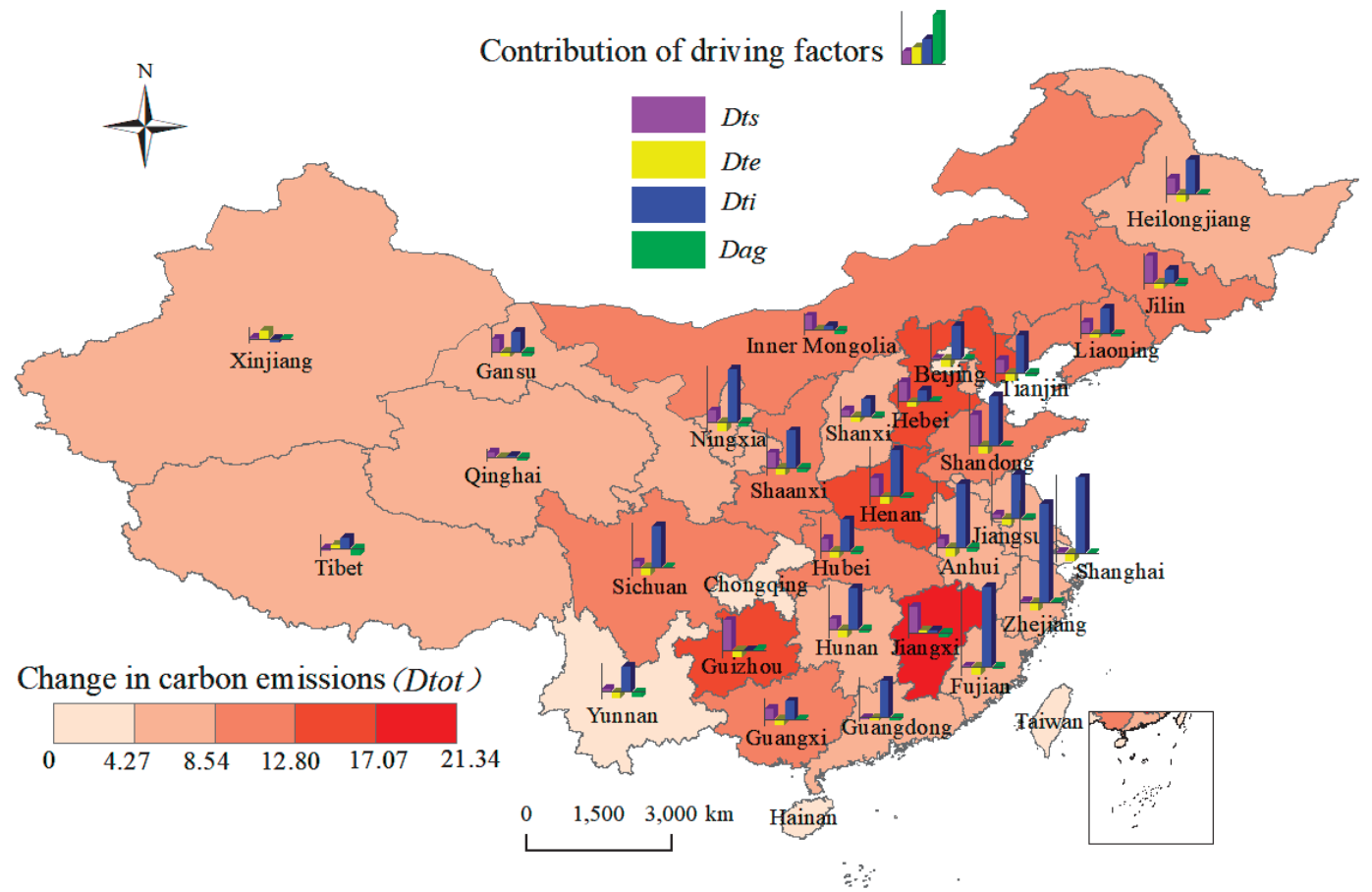

Fig. 3. Driving factors of logistics carbon emissions (2003-2018). 
Table 1. Driving effect of transport structure and its temporal variation.

\begin{tabular}{|c|c|c|c|c|c|}
\hline Province & $2003-2018$ & $2003-2007$ & $2007-2011$ & 2011-2015 & $2015-2018$ \\
\hline Beijing & 1.05 & 0.83 & 1.04 & 1.26 & 0.97 \\
\hline Tianjin & 2.34 & 0.89 & 2.06 & 1.27 & 1.01 \\
\hline Hebei & 2.93 & 0.74 & 2.94 & 0.98 & 1.04 \\
\hline Shanxi & 1.54 & 1.26 & 1.00 & 1.16 & 1.06 \\
\hline Inner Mongolia & 2.41 & 1.15 & 1.99 & 1.06 & 1.00 \\
\hline Liaoning & 2.12 & 1.06 & 1.91 & 1.08 & 0.98 \\
\hline Jilin & 3.67 & 1.11 & 2.77 & 1.28 & 0.95 \\
\hline Heilongjiang & 2.59 & 1.33 & 1.81 & 1.28 & 0.85 \\
\hline Shanghai & 1.06 & 0.99 & 1.16 & 1.02 & 0.92 \\
\hline Jiangsu & 1.29 & 0.76 & 0.99 & 1.16 & 1.11 \\
\hline Zhejiang & 1.10 & 0.74 & 1.46 & 0.94 & 1.08 \\
\hline Anhui & 1.86 & 1.13 & 2.50 & 0.65 & 1.02 \\
\hline Fujian & 1.07 & 0.98 & 1.21 & 0.97 & 0.92 \\
\hline Jiangxi & 3.62 & 1.10 & 2.78 & 1.16 & 1.03 \\
\hline Shandong & 4.10 & 1.19 & 2.70 & 1.31 & 0.98 \\
\hline Henan & 2.87 & 1.15 & 2.66 & 0.94 & 1.00 \\
\hline Hubei & 2.21 & 0.99 & 1.74 & 1.23 & 1.05 \\
\hline Hunan & 2.03 & 1.05 & 1.53 & 1.17 & 1.08 \\
\hline Guangdong & 0.84 & 1.15 & 1.38 & 0.72 & 0.73 \\
\hline Guangxi & 2.05 & 0.92 & 1.81 & 1.20 & 1.03 \\
\hline Sichuan & 1.54 & 0.94 & 1.55 & 1.08 & 0.99 \\
\hline Guizhou & 4.04 & 1.23 & 1.77 & 1.67 & 1.12 \\
\hline Yunnan & 1.28 & 0.97 & 1.07 & 1.19 & 1.05 \\
\hline Tibet & 0.81 & 0.92 & 0.75 & 1.21 & 0.97 \\
\hline Shaanxi & 2.50 & 1.01 & 2.29 & 1.07 & 1.02 \\
\hline Gansu & 2.35 & 0.84 & 2.14 & 1.27 & 1.04 \\
\hline Qinghai & 1.48 & 0.94 & 1.67 & 0.94 & 1.01 \\
\hline Ningxia & 2.16 & 1.01 & 2.33 & 1.04 & 0.89 \\
\hline Xinjiang & 1.09 & 0.92 & 1.12 & 1.13 & 0.93 \\
\hline Average & 2.07 & 1.01 & 1.80 & 1.12 & 0.99 \\
\hline
\end{tabular}

Liaoning, the technical intensity effect declined from that of the previous stage, indicating that the positive promotion of carbon emissions by technical intensity in these regions tended to weaken, with the energy-savings effect of technical intensity starting to over-perform its rebound effect.

Table 4 lists the driving effect of industry agglomeration and its time-series change. From 2003 to 2018 , the average value of the industry agglomeration effect was 0.73 , showing an inhibiting effect on carbon emissions. Viewed in stages, the industry agglomeration effect showed a volatile downward trend. From 2003 to
2007, except for Hebei and Guizhou, the value of the industry agglomeration effect was less than 1, indicating that the carbon reduction effect was emerging during this period. However, from 2007 to 2011, the carbon reduction effect was weakened due to the impact of the global financial crisis in 2008. From 2011 to 2015, the industry agglomeration effect in some provinces, such as Beijing and Tianjin, fell below 1, allowing the second emergence of the driving effect on logistics carbon reductions. From 2015 to 2018, the value of industry agglomeration rebounded slightly, with a weakened carbon reduction effect. 
Table 2. Driving effect of technical efficiency and its temporal variation.

\begin{tabular}{|c|c|c|c|c|c|}
\hline Province & $2003-2018$ & $2003-2007$ & $2007-2011$ & 2011-2015 & 2015-2018 \\
\hline Beijing & 0.16 & 0.90 & 0.69 & 0.46 & 0.58 \\
\hline Tianjin & 0.15 & 0.90 & 0.62 & 0.49 & 0.55 \\
\hline Hebei & 0.50 & 1.34 & 1.25 & 0.59 & 0.51 \\
\hline Shanxi & 0.38 & 1.23 & 0.74 & 0.45 & 0.93 \\
\hline Inner Mongolia & 1.08 & 1.46 & 2.30 & 0.46 & 0.70 \\
\hline Liaoning & 0.55 & 1.32 & 1.23 & 0.47 & 0.73 \\
\hline Jilin & 0.42 & 1.03 & 1.85 & 0.52 & 0.57 \\
\hline Heilongjiang & 0.14 & 0.77 & 0.81 & 0.44 & 0.74 \\
\hline Shanghai & 0.11 & 0.83 & 0.34 & 0.51 & 0.76 \\
\hline Jiangsu & 0.25 & 0.86 & 1.11 & 0.47 & 0.57 \\
\hline Zhejiang & 0.14 & 0.95 & 0.76 & 0.41 & 0.47 \\
\hline Anhui & 0.40 & 0.41 & 1.95 & 0.54 & 0.75 \\
\hline Fujian & 0.17 & 1.37 & 0.56 & 0.45 & 0.48 \\
\hline Jiangxi & 1.29 & 1.15 & 2.60 & 0.85 & 0.51 \\
\hline Shandong & 0.09 & 0.80 & 1.08 & 0.20 & 0.55 \\
\hline Henan & 0.20 & 1.15 & 1.31 & 0.30 & 0.44 \\
\hline Hubei & 0.33 & 0.75 & 1.04 & 0.50 & 0.85 \\
\hline Hunan & 0.15 & 1.02 & 0.74 & 0.29 & 0.69 \\
\hline Guangdong & 0.62 & 0.58 & 0.97 & 1.35 & 0.82 \\
\hline Guangxi & 0.41 & 0.88 & 1.52 & 0.40 & 0.73 \\
\hline Sichuan & 0.19 & 1.49 & 0.91 & 0.38 & 0.36 \\
\hline Guizhou & 0.34 & 1.15 & 0.88 & 0.54 & 0.63 \\
\hline Yunnan & 0.40 & 1.21 & 0.59 & 0.63 & 0.89 \\
\hline Tibet & 1.38 & 1.02 & 0.76 & 2.11 & 0.84 \\
\hline Shaanxi & 0.24 & 0.80 & 1.05 & 0.53 & 0.54 \\
\hline Gansu & 0.47 & 1.22 & 1.42 & 0.43 & 0.63 \\
\hline Qinghai & 0.94 & 1.22 & 2.33 & 0.46 & 0.72 \\
\hline Ningxia & 0.12 & 0.82 & 2.24 & 0.33 & 0.20 \\
\hline Xinjiang & 1.75 & 1.53 & 1.75 & 0.79 & 0.83 \\
\hline Average & 0.46 & 1.04 & 1.22 & 0.56 & 0.64 \\
\hline
\end{tabular}

\section{Spatial Dynamics Trajectories of Driving Effects}

We adopted the gravity center model to explore the change in the trajectory of the gravity center of logistics carbon emissions and their driving effects (Fig. 4). During the sampling period, the gravity center of the logistics carbon emissions experienced a shift from the northeast to the southwest. Specifically, from 2004 to 2011, this gravity center shifted from Zhumadian City to the northeast. The underlying reason was the strategy of revitalizing the old northeast industrial base, as well as the implementation of the
Bohai Rim Economic Circle in 2002. The leapfrog development of the economy in northeast China expanded the development scale of the logistics industry and caused a continuous rise in the level of emissions in northeast China. From 2011 to 2018, the gravity center of the logistics carbon emissions started to shift to the southwest owing to the implementation of the national policy to promote development in central China.

For the dynamic trajectory of the transport structure effect, a shift from the northeast to the southwest occurred, indicating that the driving effect of the 
Table 3. Driving effect of technical intensity and its temporal variation.

\begin{tabular}{|c|c|c|c|c|c|}
\hline Province & $2003-2007$ & $2007-2011$ & 2011-2015 & $2015-2018$ & 2015-2018 \\
\hline Beijing & 4.34 & 1.28 & 1.27 & 1.74 & 1.53 \\
\hline Tianjin & 4.75 & 1.19 & 1.17 & 1.79 & 1.89 \\
\hline Hebei & 2.13 & 0.73 & 0.72 & 1.84 & 2.19 \\
\hline Shanxi & 2.69 & 1.08 & 1.05 & 2.11 & 1.12 \\
\hline Inner Mongolia & 1.38 & 0.65 & 0.61 & 1.60 & 2.16 \\
\hline Liaoning & 3.56 & 1.36 & 0.85 & 1.90 & 1.63 \\
\hline Jilin & 2.36 & 0.91 & 0.75 & 1.72 & 2.00 \\
\hline Heilongjiang & 4.44 & 1.12 & 1.54 & 1.81 & 1.42 \\
\hline Shanghai & 8.59 & 1.40 & 2.98 & 1.46 & 1.42 \\
\hline Jiangsu & 5.32 & 2.07 & 0.81 & 1.99 & 1.60 \\
\hline Zhejiang & 10.96 & 1.90 & 1.42 & 2.08 & 1.96 \\
\hline Anhui & 7.43 & 2.89 & 1.51 & 1.69 & 1.22 \\
\hline Fujian & 9.07 & 0.95 & 1.90 & 2.22 & 2.27 \\
\hline Jiangxi & 1.31 & 0.84 & 0.74 & 1.12 & 1.88 \\
\hline Shandong & 5.94 & 1.09 & 1.05 & 3.16 & 1.64 \\
\hline Henan & 5.69 & 0.77 & 2.15 & 1.44 & 2.37 \\
\hline Hubei & 4.15 & 1.44 & 1.24 & 2.08 & 1.12 \\
\hline Hunan & 5.14 & 1.01 & 1.17 & 3.19 & 1.37 \\
\hline Guangdong & 4.75 & 2.14 & 1.16 & 1.09 & 1.75 \\
\hline Guangxi & 2.86 & 1.28 & 0.74 & 2.21 & 1.48 \\
\hline Sichuan & 5.15 & 0.73 & 1.45 & 1.97 & 2.48 \\
\hline Guizhou & 1.01 & 0.49 & 0.80 & 1.56 & 1.67 \\
\hline Yunnan & 3.59 & 0.98 & 1.93 & 1.67 & 1.14 \\
\hline Tibet & 2.05 & 1.71 & 0.90 & 1.04 & 1.28 \\
\hline Shaanxi & 4.75 & 1.16 & 1.34 & 1.68 & 1.82 \\
\hline Gansu & 3.06 & 0.88 & 0.81 & 2.62 & 1.64 \\
\hline Qinghai & 1.12 & 0.75 & 0.69 & 1.49 & 1.45 \\
\hline Ningxia & 6.41 & 1.12 & 0.55 & 2.35 & 4.44 \\
\hline Xinjiang & 0.62 & 0.94 & 0.72 & 0.77 & 1.18 \\
\hline Average & 4.30 & 1.20 & 1.17 & 1.84 & 1.76 \\
\hline
\end{tabular}

transport structure on carbon reduction did not emerge. After 2011, with the support of national policies, the central and western regions continuously improved their infrastructure, while the transport structure of Guangxi, Guizhou, Gansu, Yunnan, and other western and southern regions showed a more significant promotional effect on carbon emissions compared with that of the other regions over the same period. This result showed that the gravity center of the transport structure shifted slightly to the southwest and was essentially stable in Zhengzhou City.
For the dynamic trajectory of the technical efficiency effect, the gravity center generally shifted from the northwest to the southwest. Specifically, from 2004 to 2011 , the gravity center of the technical efficiency effect shifted to the northwest, which is a manifestation of the gradual release of the strategic policy effect of development in the west. From 2011 to 2018, with increasing investments in logistics energy-savings and emission-reduction technologies in the central and western provinces, such as Henan and Sichuan, there was an increase in the carbon reduction effect of technical efficiency. 
Table 4. Driving effect of industry agglomeration and its temporal variation.

\begin{tabular}{|c|c|c|c|c|c|}
\hline Province & 2003-2018 & 2003-2007 & 2007-2011 & 2011-2015 & 2015-2018 \\
\hline Beijing & 0.82 & 0.77 & 1.19 & 0.84 & 1.26 \\
\hline Tianjin & 0.59 & 0.71 & 1.06 & 0.79 & 0.99 \\
\hline Hebei & 1.03 & 1.02 & 1.19 & 0.96 & 0.88 \\
\hline Shanxi & 0.76 & 0.86 & 0.90 & 1.05 & 0.95 \\
\hline Inner Mongolia & 0.57 & 0.73 & 1.03 & 0.85 & 0.9 \\
\hline Liaoning & 0.70 & 0.77 & 1.04 & 0.99 & 0.88 \\
\hline Jilin & 0.68 & 0.69 & 0.92 & 0.95 & 1.13 \\
\hline Heilongjiang & 0.96 & 0.90 & 0.94 & 1.05 & 1.09 \\
\hline Shanghai & 0.96 & 0.93 & 1.00 & 1.00 & 1.23 \\
\hline Jiangsu & 0.68 & 0.64 & 1.31 & 0.90 & 0.92 \\
\hline Zhejiang & 0.87 & 0.78 & 1.13 & 1.03 & 0.96 \\
\hline Anhui & 0.51 & 0.71 & 0.84 & 0.94 & 0.9 \\
\hline Fujian & 0.74 & 0.75 & 0.98 & 1.09 & 0.92 \\
\hline Jiangxi & 0.57 & 0.72 & 0.90 & 0.93 & 0.95 \\
\hline Shandong & 0.94 & 0.93 & 1.19 & 0.78 & 1.09 \\
\hline Henan & 0.76 & 0.79 & 0.75 & 1.38 & 0.94 \\
\hline Hubei & 0.62 & 0.68 & 1.03 & 0.95 & 0.92 \\
\hline Hunan & 0.67 & 0.73 & 1.18 & 0.85 & 0.92 \\
\hline Guangdong & 0.64 & 0.58 & 1.06 & 1.06 & 0.99 \\
\hline Guangxi & 0.87 & 0.75 & 1.32 & 0.94 & 0.94 \\
\hline Sichuan & 0.99 & 0.94 & 0.97 & 1.03 & 1.06 \\
\hline Guizhou & 1.19 & 1.25 & 1.28 & 0.85 & 0.88 \\
\hline Yunnan & 0.41 & 0.63 & 0.72 & 0.92 & 0.98 \\
\hline Tibet & 0.30 & 0.50 & 0.97 & 0.79 & 0.8 \\
\hline Shaanxi & 0.55 & 0.72 & 0.94 & 0.90 & 0.91 \\
\hline Gansu & 0.54 & 0.80 & 1.03 & 0.73 & 0.9 \\
\hline Qinghai & 0.69 & 0.79 & 0.96 & 0.93 & 0.98 \\
\hline Ningxia & 0.56 & 0.70 & 1.36 & 0.84 & 0.71 \\
\hline Xinjiang & 1.04 & 0.64 & 0.94 & 1.50 & 1.16 \\
\hline Average & 0.73 & 0.77 & 1.04 & 0.96 & 0.97 \\
\hline
\end{tabular}

For the dynamic trajectory of the technical intensity effect, the gravity center shifted longitudinally eastward. Specifically, from 2004 to 2011, the gravity center of the technical intensity effect shifted to the southeast, opposite of the center of carbon emissions in the latitudinal direction. From 2011 to 2018, the focus of technical intensity shifted further eastward, but gradually shifted to the north, which was related to the technology rebound effect in Hebei, Inner Mongolia, Jilin, and other eastern and northern regions.

For the dynamic trajectory of the industry agglomeration effect, the gravity center shifted westward in the warp direction and fluctuated from north to south in the latitudinal direction. Compared with other driving factors, the shift in its gravity center was relatively small, concentrated basically in Luoyang City, Henan Province. Specifically, from 2004 to 2015, the carbon reduction effect of industry agglomeration was prominent in Tibet, Yunnan, and other western and southern regions. The gravity center shifted to the southwest, the opposite of the shifting trajectory of carbon emissions. From 2015 to 2018, industry agglomeration in the eastern and northern regions, such as Beijing, Jilin, and Heilongjiang, began to 


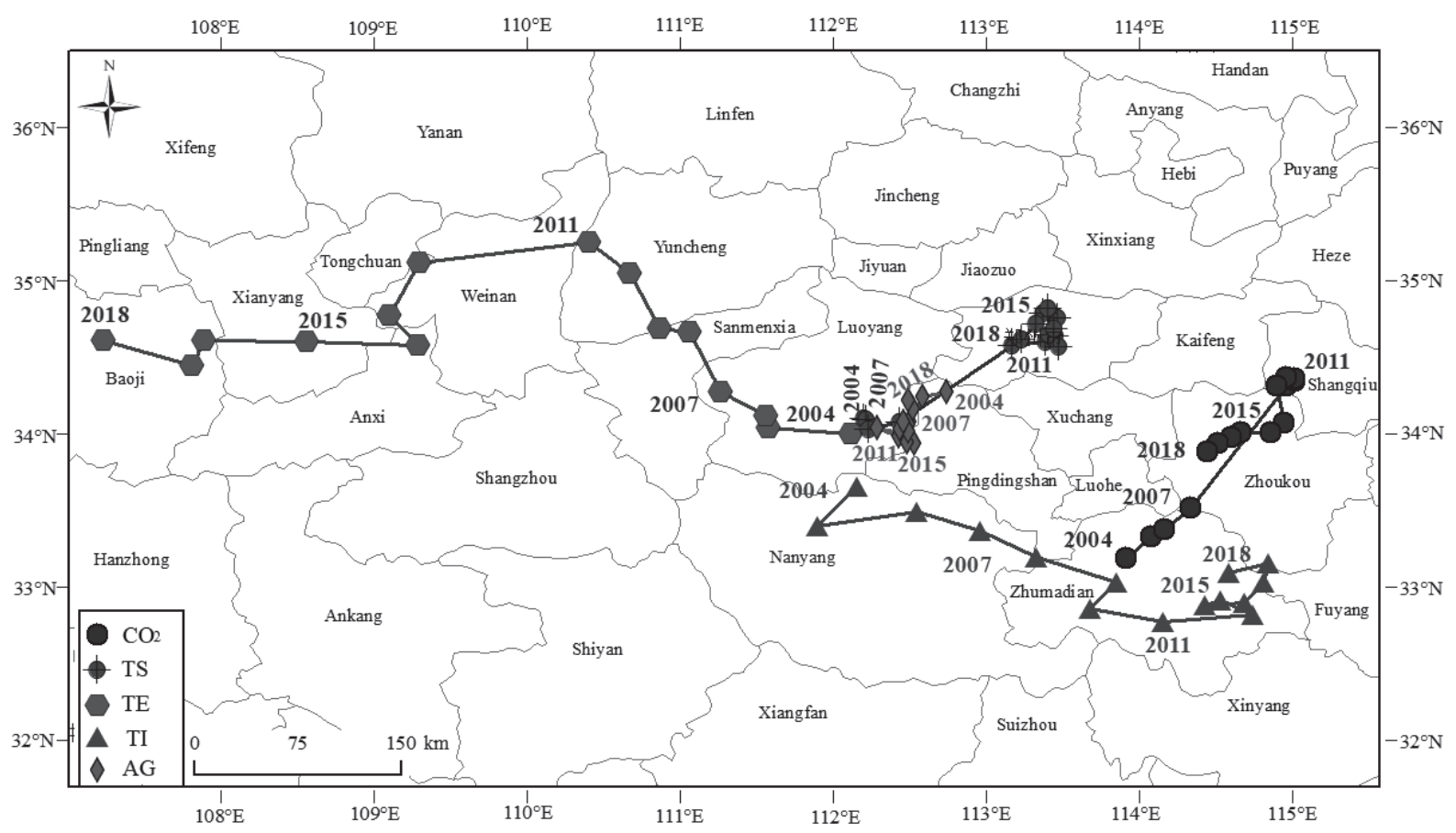

Fig. 4. Gravity center shift trajectory in logistics carbon emissions and its driving effects.

show a congestion effect. The excessive agglomeration of logistics resources led to an increase in the carbon emissions, such that the gravity center of the industry agglomeration effect shifted slightly to the northeast.

\section{Discussion}

Compared with previous research, Luo et al. [22] used the LMDI decomposition method to decompose the driving factors of carbon emissions in the freight transportation field into energy structure, transportation mode, freight intensity, economic growth, and population. In this study, an extended GFI model was adopted. In addition to transportation structure, logistics technology innovation, logistics industry agglomeration, and other factors were incorporated. The logistics industry itself was taken as the breakthrough point to reveal the driving factors of carbon emissions on the logistics industry level, which is a major contribution of this study.

The decomposition results of the driving factors of China's logistics carbon emissions showed that the transportation structure was the key driving factor in the growth of logistics carbon emissions. The light industry and manufacturing in China have become increasingly dependent on road transportation due to the inadequacies of the freight railway transportation network. According to Tian et al., [32] road transportation generates the highest carbon emissions in the freight transportation sector in China, accounting for $85 \%$ of the total logistics carbon emissions. Moreover, the temporal variation trend in the transport structure effect indicated that transport structure adjustments started to benefit reductions in logistics carbon emissions in China. An improved transport structure could play a positive role in reducing carbon emissions [33].

While technical efficiency played a key role in limiting energy consumption and promoting reductions in carbon emissions, a previous study reported that an improved technical efficiency can improve carbon emission efficiencies and reduce carbon emissions [34]. However, improvements to the technical efficiency do not always lead to a carbon emission reduction. Instead, it may promote a growth in logistics carbon emissions. The key to this phenomenon is whether carbon reductions are the main target of investments in logistics technology research and development [35]. Compared with a general target technical innovation, low carbon biased technological innovation more strongly promotes the reduction of carbon emissions [36].

On the contrary, technology intensity was the dominant factor promoting the growth of logistics carbon emissions. Technical innovation activities have a rebound effect by expanding the scale of the logistics industry, subsequently promoting growth in carbon emissions [37]. Particularly in eastern coastal areas, such as Zhejiang, Fujian, and Shanghai, the rebound effect of technical intensity offset its energysaving effect to ultimately become the primary driver of logistics carbon emissions.

Industry agglomeration was another key driving factor to curb logistics carbon emissions, verifying the conclusions of Kaya [31]. According to Zeng et al., [38] industry agglomeration could achieve scale 
and technology spillover effects through information exchange, resource integration, and capacity sharing, thereby reducing logistics carbon emissions. Drucker and Feser [39] proposed that the crowding effect of industrial agglomeration may also contribute to the growth of carbon emissions. The decomposition results in this study showed that the carbon emission reduction effect of industrial agglomeration occasionally weakened due to two reasons: first, under the impact of the 2008 financial crisis, several small- and mediumsized logistics enterprises struggled to survive, so that the level of industry agglomeration and carbon reduction effects declined. Second, with the rapid economic development, agglomerations of the logistics industry in relatively developed areas, such as Beijing and Shanghai, approached a saturation level, and an overcrowding effect emerged, which partially offset the carbon reduction effect of industry agglomeration.

Another key innovation of our current study is that we also explored spatial dynamic trajectories of driving factors. We found that the effects of different driving factors showed spatially heterogeneous dynamics.

The gravity center shift trajectory of the transportation structure effect was essentially the same as that of logistics carbon emissions: moving from northeast to southwest. According to Zhang et al., [40] an increasing proportion of road and air transport was the main reason for high logistics carbon emissions in China. Therefore, our results for the gravity center shift trajectory of the transportation structure effect indicated that road and air transportation in the southwestern region occupied a dominant position in the transportation structure, while the transportation structure in the northeast region tended to be optimized toward carbon emission reductions.

The gravity center of technical efficiency shifted from the north to the south in the latitudinal direction as well as further westward in the meridional direction. The trajectory tended to converge with that of logistics carbon emissions, which verified the results that technical efficiency does not always reduce carbon emissions [41]. Technological innovation activities in the southwestern region are mainly aimed at promoting economic growth, rather than at energy conservation and emission reduction. The emission reduction effects of technological innovation have been weakened in the southwestern region. Additionally, the magnitude of the east-west shift was relatively large, implying a relatively notable spatial difference in the technical efficiency effect between the east and west.

The gravity center shift trajectory of the technical intensity effect was consistent with the shifting path of logistics carbon emissions. The results in this study show that the positive effect of technical intensity on logistics carbon emissions mainly affected the southeastern region, whereas the positive effect on the northern region was relatively weak. This finding is directly related to increasing technical investments that served to improve the logistics service capabilities and met logistics needs in the southeastern region.

The gravity center of the industry agglomeration effect was opposite to that of carbon emissions, showing a shifting trend from the southwest to the northeast. This verifies the decomposition results of the GFID model. Zeng and Zhao [42] built a spatial economic growth model and found that industrial agglomeration can alleviate the pollution paradise effect to a certain extent. Another study put forward that agglomeration plays an important role in promoting a local green development. Under the adjustment of the mechanisms of city size and openness, the impact of agglomeration on the efficiency of a green development shows a "gradient" enhancement [43]. Thus, we conclude that the carbon emission reduction effect of industry agglomeration played a dominant role.

Our results show that the driving factors of carbon emission reductions in the logistics industry manifest themselves on a regional level, so that regional cooperation should be encouraged to solve each driving factor to reduce carbon emissions. Relevant research should focus on the measurement of regional differences in each driving effect and provide a theoretical basis for carbon emission reductions in the logistics industry from a spatial dimension. Another issue to focus on is the impact of the microeconomic behaviors of logistics enterprises on carbon emissions, so as to render the research results more applicable.

\section{Conclusions and Policy Implications}

\section{Conclusions}

The nature of business of the logistics leads to the sector having high-carbon characteristics. However, developing low-carbon logistics requires an understanding of the driving factors of carbon emissions as well as their spatial and temporal dynamics. Based on the CUTE model, this study identified the driving factors of China's logistics carbon emissions and adopted the GFID model to decompose the driving effects of each factor. Finally, combined with the gravity model to explore the dynamic trajectory of the driving effects, the main conclusions are as follows:

Technical intensity and transport structure actively promoted logistics carbon emissions. The effect of transport structure showed an upward trend and then a downward trend, implying that a carbon reduction effect of the transport structure was emerging. However, the impact of technical intensity on carbon growth increased due to the rebound effect of technology. In contrast, technical efficiency and industry agglomeration were found to be important driving factors to curb logistics carbon emissions. Specifically, the technical efficiency effect showed an $\mathrm{N}$-shaped change, while the industry agglomeration effect showed a downward trend, 
indicating that the inhibitory effect gradually became prominent.

The driving effects of various factors on carbon emissions had an obvious spatial heterogeneity. First, the shift in the logistics carbon emission center from northeast to southwest was accompanied by the same directional shift in the gravity center of the transport structure effect. This result showed that transport structure was still the main driving factor of logistics carbon emissions; therefore, the transport structure has to be further optimized in the future to achieve carbon reductions in the logistics industry. Second, the gravity center of the technology efficiency effect shifted from the northwest to the southwest, first showing a divergence and then a convergence tendency with the gravity center of logistics carbon emissions. Technical efficiency did not always inhibit the growth of logistics carbon emissions, and its effect depends on whether the purpose of implementing technical innovation activities in various regions is to promote economic growth or reduce carbon emissions. The gravity center of the technical intensity effect shifted eastward, which was consistent with the transfer path of the gravity center of carbon emissions in the longitudinal direction, i.e., the technical intensity of the eastern region had a dominant role in promoting carbon emissions in China's logistics industry. Lastly, the gravity center shift trajectory of industrial agglomeration was opposite to that of logistics carbon emissions. Therefore, industrial agglomeration is a key driving factor leading to carbon emission reductions in the logistics industry.

\section{Policy Implications}

Based on the above results, we provide several policy recommendations to promote carbon emission reductions in China's logistics industry.

(1) Adjustment of transport structure. A high proportion of the logistics industry in China comprises road transportation; therefore, encouraging an ecofriendly transportation could be an effective measure to curb emissions. On the one hand, the railway network and railway service system could be improved. Railways and industrial parks should be connected to enhance the flexibility and accessibility of the railway transportation network and realize the transition from road to railway transportation. On the other hand, multimodal transportation could be encouraged, and effective connections from rail and water transportation to the places of origin or destination of goods could be explored. In this way, a reasonably comprehensive transportation system could be built.

(2) Promotion of green technology innovation. Promoting technical innovation is a fundamental method to reduce logistics carbon emissions. Without policy intervention, the aim of logistics technology research and development is often to improve logistics service capabilities, which not only violates the principles of a coordinated economic and environmental development but is also detrimental to carbon reduction effects. Therefore, the government should strengthen the guiding role of fiscal policies on logistics carbon reductions, formulate corresponding fiscal and taxation policies and incentive measures, encourage the logistics industry towards energy conservation and lowcarbon emissions, and further promote logistics green technology innovation related to energy conservation and emission reduction. In addition, relevant government departments could implement various regulatory policy tools, such as carbon labeling, carbon emission audits, and carbon reduction responsibility sharing to encourage logistics companies to improve their carbon reduction effects through green technical innovation.

(3) Improvement in the industry agglomeration level. Compared with the inhibitory effect of technical efficiency on logistics carbon emissions, the carbon reduction effect of industry agglomeration was relatively insignificant. From another perspective, this result indicated a substantial future potential for industry agglomeration in logistics carbon reductions. As various provinces in the eastern region are becoming congested, logistics companies should be directed to relatively underdeveloped areas in their vicinity. With respect to the central and western regions that are still at an agglomeration low-level, the following measures should continue, namely vigorously developing the economy of urban agglomerations, promoting regional economic integration, breaking down trade barriers between regions, supporting the construction of logistics industrial parks and, in particular, increasing the spatial concentration of logistics activities. It is crucial to focus on improving the logistics concentration level in the central and western regions to aid them in reaching an ideal stage to fully develop the effects of energy conservation and emission reduction.

(4) Maximizing the strengths and avoiding weaknesses and fully developing the carbon reduction effects of each driving factor are critical aspects for a green and coordinated development of the logistics industry. Therefore, relevant government departments should comprehensively consider the spatial change trajectory of each driving effect, combine regional differences in the driving effects, affect mutual assistance and cooperation between regions, learn from the relatively mature experience of logistics carbon emission reduction, and formulate policies and targets for energy conservation and emission reduction in the logistics industry in accordance with the actual situation of the region.

\section{Acknowledgments}

This work was supported by the National Social Science Foundation of China (No. 18BGL018). 


\section{Conflicts of Interest}

The authors declare that they have no competing interests.

\section{References}

1. CETIN M. A Change in the amount of $\mathrm{CO}_{2}$ at the center of the examination halls: Case Study of Turkey. Studies on Ethno-Medicine, 10 (2), 146, 2016.

2. CETIN M., SEVIK H., SAAT A. Indoor air quality: The samples of Safranbolu Bulak Mencilis cave. Fresenius Environmental Bulletin, 26 (10), 5965, 2017.

3. CETIN M., SEVIK H. Measuring the impact of selected plants on indoor $\mathrm{CO}_{2}$ concentrations. Polish Journal of Environmental Studies, 25 (3), 973, 2016.

4. CANSINO J.M., ROMÁN R., ORDÓÑEZ M. Main drivers of changes in $\mathrm{CO}_{2}$ emissions in the Spanish economy: A structural decomposition analysis. Energy Policy, 89, 150, 2016.

5. CHANG C., DONG M., SUI B., CHU Y. Driving forces of global carbon emissions: From time-and spatial-dynamic perspectives. Economic Modelling, 77, 70, 2019.

6. ROSE A., CHEN C. Sources of change in energy use in the US economy, 1972-1982: a structural decomposition analysis. Resources and Energy, 13 (1), 1, 1991.

7. WOOD R. Structural decomposition analysis of Australia's greenhouse gas emissions. Energy Policy, 37 (11), 4943, 2009.

8. ANG B.W. Decomposition analysis for policymaking in energy: Which is the preferred method? Energy Policy, 32 (9), 1131, 2004.

9. FISHER I. The making of index numbers. Boston: Houghton Mifflin, 1922.

10. ANG B. W., LIU F.L., CHUNG H. A generalized Fisher index approach to energy decomposition analysis. Energy Economics, 26, 757, 2004.

11. TONG X., LI X., TONG L., CHEN K. Spatial-time evolution of carbon emission patterns in china: based on dynamic evolution and spatial agglomeration. Journal of Northeastern University Natural Science, 37 (11), 1668, 2016.

12. ZHANG N., WEI X. Dynamic total factor carbon emissions performance changes in the Chinese transportation industry. Applied Energy, 146, 409, 2015.

13. PEI J., NIU Z., WANG L., SONG X., HUANG N., GENG J., WU Y. Spatial-temporal dynamics of carbon emissions and carbon sinks in economically developed areas of China: a case study of Guangdong Province. Scientific Reports, 8 (1), 13383, 2018.

14. GROSSMAN G.M., KRUEGER A.B. Environmental impacts of a North American free trade agreement. CEPR Discussion Papers, 8 (2), 223, 1992.

15. HAYASHI Y., NAKAMURA K. Climate change, mobility and cost of transport. Transport Policy, 29, 261, 2013.

16. LUO X., DONG L., DOU Y., LI Y., LIU K., REN J., LIANG H., MAI X. Factor decomposition analysis and causal mechanism investigation on urban transport $\mathrm{CO}_{2}$ emissions: Comparative study on Shanghai and Tokyo. Energy Policy, 107, 658, 2017.

17. YAO X., PAN S., SONG C. City size, spatial agglomeration and electricity intensity in China. Economic Research Journal. 10, 165, 2017 [In Chinese].
18. ZHANG L., RONG P., QIN Y., JI Y. Does industrial agglomeration mitigate fossil $\mathrm{CO}^{2}$ emissions? An empirical study with spatial panel regression model. Energy Procedia, 152, 731, 2018.

19. EHRENFELD J. Putting a spotlight on ehrenfeld and analogies in industrial ecology. Journal of Industrial Ecology, 7 (1), 1, 2003.

20. WEN Y., LIAO M. The impact of industrial agglomeration on carbon emissions: Empirical evidence from China. International Journal of Management and Sustainability, 8 (2), 67, 2019.

21. CHEN J., XU C., SONG M., LIU X. Driving factors of China's energy productivity and its spatial character: Evidence from 248 cities. Ecological Indicators, 90, 18, 2018.

22. DAI Y., GAO H.O. Energy consumption in China's logistics industry: A decomposition analysis using the LMDI approach. Transportation Research Part D: Transport and Environment, 46, 69, 2016.

23. SAIDI S., HAMMAMI S. Modeling the causal linkages between transport,economic growth and environmental degradation for 75 countries. Transportation Research Part D, 53, 415, 2017.

24. LUO X., DONG L., DOU Y., LIANG H., REN J., FANG $\mathrm{K}$. Regional disparity analysis of Chinese freight transport $\mathrm{CO}_{2}$ emissions from 1990 to 2007: Driving forces and policy challenges. Journal of Transport Geography, 56, 1, 2016.

25. GUO M., MENG J. Exploring the driving factors of carbon dioxide emission from transport sector in Beijing-TianjinHebei region. Journal of Cleaner Production, 226, 692, 2019.

26. SHAO S., YANG L., GAN C., CAO J., GENG Y., GUAN D. Using an extended LMDI model to explore technoeconomic drivers of energy-related industrial $\mathrm{CO}_{2}$ emission changes: A case study for Shanghai (China). Renewable and Sustainable Energy Reviews, 55, 516, 2016.

27. CUI Q., LI Y. An empirical study on the influencing factors of transportation carbon efficiency: Evidences from fifteen countries. Applied Energy, 141, 209, 2015.

28. YANG L., LI Z. Technology advance and the carbon dioxide emission in China - Empirical research based on the rebound effect. Energy Policy, 101, 150, 2017.

29. IPCC (Intergovernmental Panel on Climate Change). IPCC guidelines for national greenhouse gas inventories. IGES: Kanagawa Prefecture, 2006.

30. KAYA Y. Impact of carbon dioxide emission control on GNP growth: Interpretation of proposed scenarios. Paris: IPCC Energy and Industry Subgroup, Response Strategies Working Group, 1990.

31. SHUAI S., LIU J., YONG G., ZHUANG M., YANG Y. Uncovering driving factors of carbon emissions from China's mining sector. Applied Energy, 166, 220, 2016.

32. TIAN Y., ZHU Q., LAI K., LUN Y.H.V. Analysis of greenhouse gas emissions of freight transport sector in China. Journal of Transport Geography, 40, 43, 2014.

33. XU B., LIN B. Investigating the differences in $\mathrm{CO}_{2}$ emissions in the transport sector across Chinese provinces: Evidence from a quantile regression model. Journal of Cleaner Production, 175, 109, 2018

34. YU S., ZHENG S., ZHANG X., GONG C., CHENG J. Realizing China's goals on energy saving and pollution reduction: Industrial structure multi-objective optimization approach. Energy Policy, 122, 300, 2018.

35. HUANG J., LIU Q., CAI X., HAO Y., LEI H. The effect of technological factors on China's carbon intensity: 
New evidence from a panel threshold model. Energy Policy, 115, 32, 2018.

36. LIU X., ZHANG X. Industrial agglomeration, technological innovation and carbon productivity: Evidence from China. Resources, Conservation \& Recycling, 166, 105330, 2021.

37. JEVONS W.S. The coal question: an inquiry concerning the progress of the nation and the probable exhaustion of our coal-mines. London: Macmillan, 1866.

38. ZENG G., GENG C., GUO H. Spatial spillover effect of strategic emerging industry agglomeration and green economic efficiency in China. Polish Journal of Environmental Studies, 29 (5), 3901, 2020.

39. DRUCKER J., FESER E. Regional industrial structure and agglomeration economies: An analysis of productivity in three manufacturing industries. Regional Science \& Urban Economics, 42 (1), 1, 2015.
40. ZHANG X., KANG F., GE J., LIU J., WANG, P. Discussion on countermeasures of developing railway commercial automobile logistics under highway overload control. Railway Transport and Economy, 39 (3), 22, 2017. [In Chinese].

41. KANG Z., LI K., QU J. The path of technological progress for China's low-carbon development: Evidence from three urban agglomerations. Journal of Cleaner Production, 178, 644, 2018.

42. ZENG D.Z., ZHAO L. Pollution havens and industrial agglomeration. Journal of Environmental Economics \& Management, 58 (2), 141, 2009.

43. YUAN H., FENG Y., LEE J., LIU H., LI R. The spatial threshold effect and its regional boundary of financial agglomeration on green development: A case study in China. Journal of Cleaner Production, 244, 118670, 2020. 